\title{
Assessment of Humidification Performance: Still No Easy Method!
}

All authors agree that humidification of gas delivered to patients during mechanical ventilation is essential. ${ }^{1}$ The upper airways normally provide $75 \%$ of the heat and moisture supplied to the alveoli. ${ }^{2}$ When bypassed, humidification of the gas is necessary to prevent hypothermia, inflammation of the airway epithelium, bronchospasm, atelectasis, and airway obstruction. ${ }^{1}$ There is, however, still a debate on how gases should be heated and humidified. ${ }^{3} \mathrm{~A}$ recent study by Moran et al showed that endotracheal tube resistance increased by $53 \%$ after a mean of 10 days of mechanical ventilation. ${ }^{4}$ This study included 22 patients with heat and moisture exchangers (HMEs) and 22 patients with heated humidifier, and similar increases in resistance were present in both groups, demonstrating that, even with the latest generations of heated humidifiers and HMEs, optimal humidification may not be attained.

The American Association for Respiratory Care recently published recommendations that also may be subject to debate. ${ }^{5}$ As it was raised by Branson and Campbell several years ago, some authors have entirely different views on the same subject, and this remains true for humidification. ${ }^{6}$ One reason relates to the absence of an accepted gold standard for humidity measurements. Among the different techniques (eg, gravimetry, psychrometry, capacitance hygrometer, infrared hygrometer), there is still no clear consensus on how humidity should be measured. The gravimetric method, despite being used as a basis for the International Standards Organization (ISO) standard for humidification device testing, ${ }^{7}$ is very difficult to use correctly, as calibration issues with the weight and volume measurements may limit its accuracy. ${ }^{8}$ When compared to an independent assessment of humidification performances, the results provided by the ISO method may provide large over-estimates 9 : up to $8.9 \mathrm{mg}_{2} \mathrm{O} / \mathrm{L} .{ }^{10}$ The questions regarding humidification during mechanical ventilation are thus still subject to debate.

The performance of humidification devices has been studied mainly during endotracheal mechanical ventilation and noninvasive ventilation; however, they have been sparsely studied for tracheostomized patients. In this issue of ReSPIRATORY CARE, 2 studies focus on the humidification performance of humidifying devices for tracheostomized patients. Chikata et al present a bench study to evaluate HMEs used for tracheostomized patients with spontaneous breathing. ${ }^{11}$ They evaluated 11 HMEs, a high-flow CPAP system, and an oxygen mask with a nebulizer heater. In a lung model they evaluated different conditions: tidal volumes of 300,500 , and $700 \mathrm{~mL}$; breathing frequencies of 10 and 20 breaths/min; and oxygen delivery at 0 and $3 \mathrm{~L} / \mathrm{min}$. They measured the absolute and relative humidity with a capacitance hygrometer. Among the tested HMEs, Chikata et al report absolute humidity varying from 25.3 to $30.7 \mathrm{mg} \mathrm{H}_{2} \mathrm{O} / \mathrm{L}$, with most values being 3-6 mg $\mathrm{H}_{2} \mathrm{O} / \mathrm{L}$ higher than the manufacturer's data. With the high-flow CPAP system the measured absolute humidity was $37.7 \pm 2.8 \mathrm{mg} \mathrm{H}_{2} \mathrm{O} / \mathrm{L}$. With nebulized heater the absolute humidity was $31.9 \pm 2.2 \mathrm{mg} \mathrm{H}_{2} \mathrm{O} / \mathrm{L}$. Administration of oxygen at $3 \mathrm{~L} / \mathrm{min}$ decreased absolute humidity, and with high tidal volumes the absolute humidity significantly decreased with all the tested HMEs, the CPAP, and the nebulized heater. However, absolute humidity was not modified by the breathing frequency.

See the Original Studies

on Pages 1442 ANd 1449

There is a need to study humidification systems used for tracheotomized patients, and Chikata et al must be congratulated on conducting such a large evaluation. However, their results must be regarded with caution, considering the method used to evaluate the humidification performance of these systems. Capacitance hygrometers are commercially available, but the results provided may be difficult to interpret. ${ }^{12}$ Indeed, variations between the minimum and maximum values of absolute humidity during inspiration with these hygrometers attain $10 \mathrm{mg} \mathrm{H}_{2} \mathrm{O} / \mathrm{L}$, limiting the interpretation of the results. ${ }^{12}$ The differences between the tested HMEs' performances and the manufacturer's data also raise questions, as previous studies showed large differences in the opposite direction. ${ }^{9,10}$ Such reported high humidification performances of the tested HME with a very low internal volume (mean internal volume of $15 \mathrm{~mL}$ ) seem difficult to attain. Finally, another limitation is that the performance evaluation of a nebulizer is a difficult task, as usual hygrometers (including capacitance hygrometers) measure water vapor contained in the gas, and not liquid droplets generated by a nebulizer. This study demonstrates the difficulty in evaluating the humidification performance of the devices used during mechanical ventilation. 
In the second study presented in this issue of RespiRATORY CARE, van den Boer et al developed an original method to measure humidification performance of HMEs for tracheostomy application. ${ }^{13}$ HMEs are passive humidifiers: during exhalation, gas is saturated with water and heated to around $32-33^{\circ} \mathrm{C},{ }^{14,15}$ water is retained on hydrophobic and/or hygroscopic elements of the HME, and during inhalation the water vapor is released into the inspired gas, so the HME gains and loses weight during breathing. Van den Boer et al postulated that this weight variation could be a simplified measure for HME performance, and they measured the HME weight and compared the results to measurements made to the ISO standard. They tested 2 HMEs for which ISO standard measures were available. Weight variations (2-6 mg variations on a total weight of around $6,290 \mathrm{mg}$ ) were measured with a microbalance. The HME was placed in an airtight box immediately after inhalation or exhalation, to prevent evaporation into the ambient air. Errors due to variation in the time required to place the HME in the container were estimated to be $<2 \%$ of the change in weight. After conditioning the HME, a measurement sequence of 25 weight observations was performed, alternating at the end of inhalation and at the end of exhalation. Different breathing patterns were tested: tidal breathing at rest, deep breathing, and shallow breathing. The absolute humidity was measured at the end of inspiration and normalized to the ambient absolute humidity. Similarly, the weight change depended on the ambient humidity, and the measurements were normalized to it. The association between breath volume, HME weight, and absolute humidity were modeled using mixed effects regression. The weight change increased linearly for small breath volumes.

From this study it appears that ex-vivo weighing of water exchange is a reliable method to measure HME performance. The method described by van den Boer et al is original and relatively simple, and it may be useful for clinical or bench measurements for HME evaluation, provided that accurate microbalances are used with precision. However, additional validations with other hygrometric methods and with other HMEs are required. This new method was compared to the gravimetric method and to previous data obtained with a fast-response capacitance hygrometer. Limitations of these hygrometers are discussed above, and other methods to measure humidity should be

\footnotetext{
The authors have disclosed no conflicts of interest.
}

Correspondence: Elise Cuquemelle MD, Respiratory ICU, Hôpital Foch, 40 rue Worth, 92151 Suresnes Cedex, France. E-mail: e.cuquemelle@ hopital.foch.org.

DOI: $10.4187 /$ respcare.02761 used to evaluate this new and original method. As discussed, there is no universally accepted method for hygrometric measurements. Another method to measure humidity is psychrometry, which has been used by several teams. ${ }^{9,10,16}$ This method, which has caused passionate debate, ${ }^{17}$ allows bench or clinical measurement of all types of humidification techniques except nebulizer. ${ }^{3}$ Its other limitation is that it is somewhat cumbersome and is intended only for research. Considering that optimal humidity is still not provided to mechanically ventilated patients, ${ }^{4}$ reliable surrogates of humidity should be developed. We are still looking for simple techniques to measure humidity during daily practice.

\section{Elise Cuquemelle MD \\ Respiratory ICU Hôpital Foch \\ Suresnes, France}

François Lellouche MD PhD

Centre de Recherche de L'Institut Universitaire de Cardiologie et de Pneumologie de Québec

Département de Médecine

Université Laval

Québec, Canada

\section{REFERENCES}

1. Ricard JD. Humidification. In: Tobin M, editor. Mechanical ventilation: McGraw-Hill; 2006:1109-1120.

2. Chatburn RL, Primiano FP Jr. A rational basis for humidity therapy (editorial). Respir Care 1987;32(4):249-254.

3. Lellouche F. Humidification during invasive mechanical ventilation: hygrometric performances and cost of humidification systems In: Esquinas AM, editor. Humidification in the intensive care unit. Berlin-Heidelberg: Springer-Verlag; 2012:137-155.

4. Moran I, Cabello B, Manero E, Mancebo J. Comparison of the effects of two humidifier systems on endotracheal tube resistance. Intensive Care Med 2011;37(11):1773-1779.

5. American Association for Respiratory Care; Restrepo RD, Walsh BK. Clinical practice guidelines. Humidification during invasive and noninvasive mechanical ventilation: 2012. Respir Care 2012;57(5): 782-788.

6. Branson RD, Campbell RS. Humidification in the intensive care unit. Respir Care Clin N Am 1998;4(2):305-320.

7. International Organization of Standards. Humidifiers for medical use. ISO 8185 1988;60:14.

8. Seakins PJ. Measuring temperature and humidity in the breathing circuit. Respir Care Clin N Am 1998;4(2):229-242.

9. Thiéry G, Boyer A, Pigné E, Salah A, De Lassence A, Dreyfuss D, Ricard JD. Heat and moisture exchangers in mechanically ventilated intensive care unit patients: a plea for an independent assessment of their performance. Crit Care Med 2003;31(3):699-704.

10. Lellouche F, Taillé S, Lefrançois F, Deye N, Maggiore SM, Jouvet $\mathrm{P}$, et al; Groupe de travail sur les Respirateurs de l'AP-HP. Humidification performance of 48 passive airway humidifiers: comparison with manufacturer data. Chest 2009;135(2):276-286. 


\section{Assessment of Humidification Performance: Still No Easy Method}

11. Chikata Y, Oto J, Onodera M, Nishimura M. Humidification performance of humidifying devices for tracheostomized patients with spontaneous breathing: a bench study. Respir Care 2013; 58(9):1442-1448.

12. Thomachot L, Viviand X, Boyadjiev I, Vialet R, Martin C. The combination of a heat and moisture exchanger and a booster: a clinical and bacteriological evaluation over $96 \mathrm{~h}$. Intensive Care Med 2002;28(2):147-153.

13. van den Boer C, Muller SH, Vincent AD, Züchner K, van den Brekel MW, Hilgers FJ. A novel, simplified ex vivo method for measuring water exchange performance of heat and moisture exchangers for tracheostomy application. Respir Care 2013;58(9):1449-1458.

14. Dery R. Humidity in anesthesiology. 3 heat and moisture patterns in the respiratory tract during anesthesia with the semi-closed system. Can Anaesth Soc J 1967;14(4):287-298.

15. Lellouche F, Qader S, Taille S, Lyazidi A, Brochard L. Underhumidification and over-humidification during moderate induced hypothermia with usual devices. Intensive Care Med 2006;32(7): 1014-1021.

16. Croci M, Elena A, Solca M. Performance of a hydrophobic heat and moisture exchanger at different ambient temperatures. Intensive Care Med 1993;19(6):351-352.

17. Ricard JD, Le Mière E, Markowicz P, Lasry S, Saumon G, Djedaïni $\mathrm{K}$, et al. Efficiency and safety of mechanical ventilation with a heat and moisture exchanger changed once a week. Am J Respir Crit Care Med 2000;161(1):104-109. 